\title{
Study on the Affecting Mechanism between Relational Risk Perception and Cooperation Innovation Project Performance*
}

\author{
Zhizhi Huang, Yue Zhuang, Chao Kong
}

School of Management, Wuhan University of Technology, Wuhan, China.

Email: hzz8921@163.com

Received June, 2013

\begin{abstract}
Nowadays, the rapid development of technology research and the trend of increasingly fierce competition change the market economy organization form of enterprise. In order to survive and develop, many companies have started to cooperate with each other. As the enterprise developing at a high speed, the high failure rate is also worthy of our attention. Many risks will emerge in the process of cooperative innovation and the relation risk is one of them. In this paper, through the empirical analysis, the effect of relation risk for team performance will be illustrated. In addition, this paper also gives some suggestions through the analysis of the results.
\end{abstract}

Keywords: Cooperative Innovation; Relational Risk; Team Performance

\section{Introduction}

As a new model of innovation, operative innovation has been widely applied in practice. As globalization and information technology developing, cooperative innovation has brought new vitality for technology innovation. For example, in order to make a difference in the smart phone market which is in the current fierce competition, 360 launched the Huawei shine, AK47 through successively cooperating with Huawei, Alcatel [1]. It is cooperation that helps 360 quickly open the mobile phone market, obtain high reputation in customers; Apple, one of the most famous companies in the world, also continuously collaborates with other makers and keeps on product innovating so that it can occupy a large market share in the world market.

Although cooperative innovation brought many benefits, such as accelerating the development of research, sharing the costs and risks of $\mathrm{R} \& \mathrm{D}$, winning the market future opportunities and so on, but for different subjects of units there is still great uncertainty in the process of cooperative innovation[2]. This uncertainty will sometimes bring huge risk to both two sides of the cooperation. Among many risks of cooperative innovation, a unique risk in the project team is defined as relational risk. The main source of relational risk is from

\footnotetext{
"Fund project: China Ministry of Education, Humanities and Social
} Sciences Research Fund (11YJA630226) the opportunistic behavior between cooperative partners. Therefore, in the cooperative innovation project team, relational risk is the primary factor to be considered. In addition, if the relational risk is out of control, it is likely to lead to project failure. What's more, the later the cooperative innovation project end the more sunk cost will be.

As the relational risk may bring many disadvantages in the process of cooperative innovation, people are more and more conscious that manager has to perceive relational risk constantly in the process of cooperation so that it can effectively reduce the influence causing by the relational risk to cooperative innovation project. Therefor e, the relational risk has become an important type of risk in the course of cooperative innovation[3]. The purpose of this study is to explore the relationship between influence factors, such as: the attitude, behavior, the level and ability of risk perception and relational risk. Then confirm the above hypothesis by empirical analysis.

\section{Review of the Literature}

After the 80s of the last century, western scholars began to study the various factors which influence the social life of people by the method of risk perception so that they could understand people's attitude towards these risk factors. Such as Xie Xiaofei (1995) in the CAS Institute of psychology found that there is a direct relational between the research of risk perception and the overall national economic situation. In other words, the 
more wealthy the country is, the more of the relevant research it would be. After nearly thirty years of development, research on risk perception has been widely used in various countries and regions, such as the United States, Britain, Germany, Canada etc. It also covers a wide range of topics, including health, security, environment, ecology and technology etc[4]. The domestic research on risk perception is mainly in the following points:

Firstly, the dispute of the name. As "risk perception" is an import, domestic studies on it is mainly by the foreign literature, and then combined with its own research in the related discussion[5]. Therefore, there are different understandings on "risk perception" or "perception of risk". The translations of these words are also different. However, no matter what the translation is, for the use of the concept, domestic scholars are referring to the expression of foreign scholars.

Secondly, research form and approach. In the international academic community, the research of risk perception mainly has four methods: the rational actor model, the psychometric paradigm, culture theory and the social amplification of risk[6]. But in our country, the scholars mainly use the psychometric paradigm and cultural theory. When study the public perception of risk, we often use the psychometric paradigm to reveal the influencing factors of risk perception. And we also do some social research, for example the questionnaire and interview, to collect the related data so that we can do some further analysis. In addition, the reason why social culture theory is more frequently used is mainly because the risk is not an objective entity, but a social, cultural building. It cannot be measured independently ignoring the environment[7].

Thirdly, the object of study of risk perception. Foreign countries started earlier for the study of risk perception. The scholars also put a greater interest in risk perception nowadays. Risk perception is a noun derived from psychology[8]. In the beginning of the study, the object of risk perception is most in the field of psychology. The cross-cultural comparative research is rarely carried on[9]. With the passage of time, the thought of risk perception is applied in all "risk" situations and a large number of research results have been achieved. Among these achievements, the economic field gets the most proportion, emergencies in sociology and public health research for more[10]. In addition, in the medicine and health field also has a certain proportion.

\section{Model Development and Hypotheses}

\subsection{Model Development}

According to the related research, we put forward the basic research model, as the Figure 1 below:

In this study, the suppositional relational is mainly composed of four major variables. They are attitude and behavior of risk perception, level and ability of risk perception, the relational risk and innovation project team performance.

As to the definition of relational risk, different scholars have defined it from different point of view. In this paper, for the need of research, the author continues to use the mature theory of relational risk, defining the relational risk from opportunism and moral hazard.

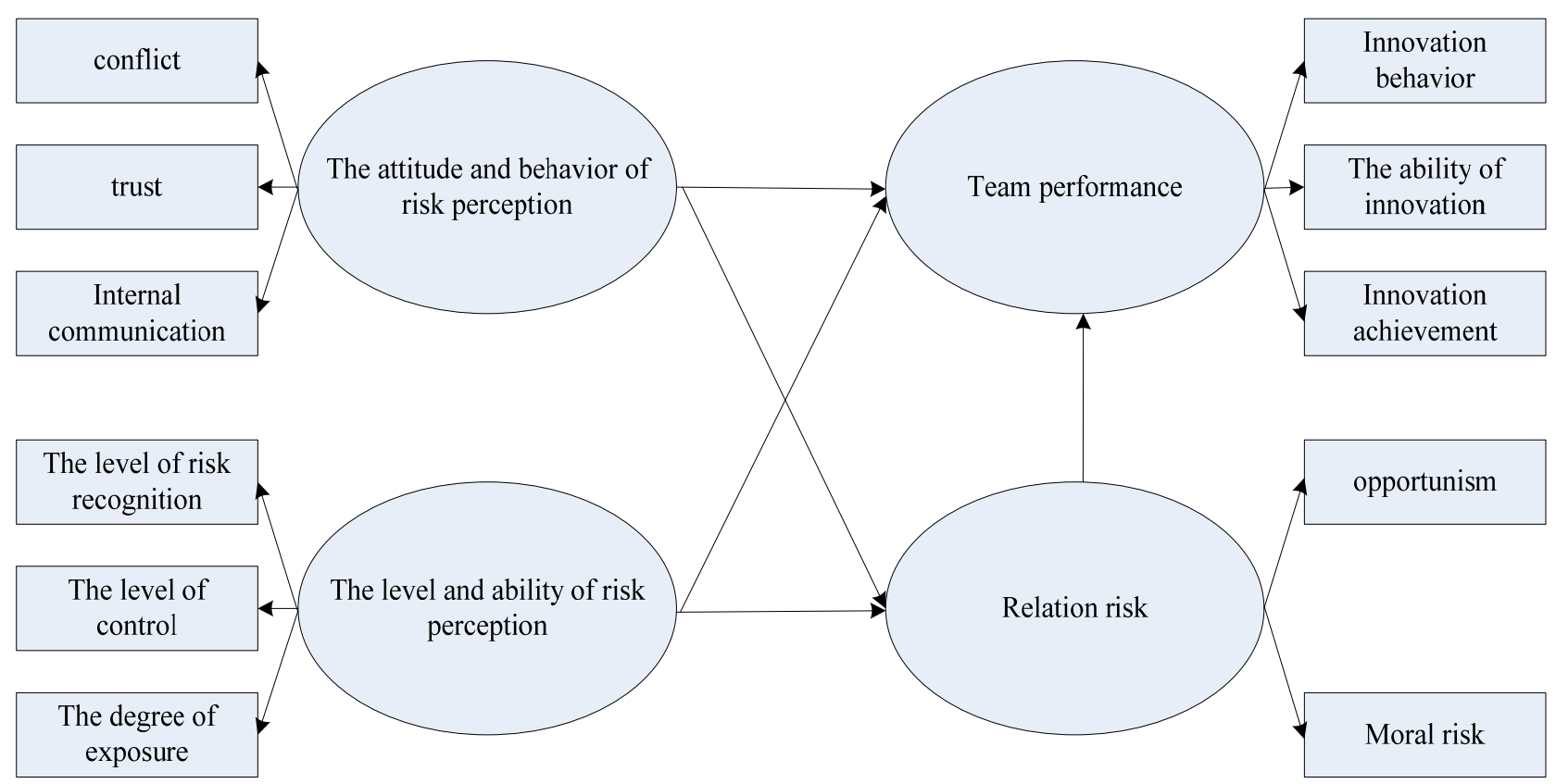

Figure 1. The framework of the study. 
About the relational risk perception: the definition of the relational risk perception in this study is different from the mainstream one. Previous scholars, including the risk perception study's sponsor Slovic, did the risk perception to specific objects. This research method will help to find the perception condition of the public to a certain perception object. However the real aim of this study is to know each employee's true attitudes and subjective feeling to the relational risk problem. Therefore, dividing the risk perception into the attitude and behavior of relational risk perception and the level of risk perception, respectively study the public's subjective cognition, attitude and psychological expectations, is more in line with the research idea.

About innovation projects team performance: According to the research of project team performance, in this section, we will measure the definition of team performance mainly from three aspects: the innovative behavior, innovation ability, innovation achievements.

\subsection{The Hypotheses}

\subsubsection{The Relationship Hypothesis between the Attitude, Behavior of Risk Perception and the Relational Risk}

In this study, the attitude, behavior of risk perception is measured by conflict, trust and communication mechanism. As is well known, in the process of cooperative innovation, intra-team conflict is inevitable. Conflict within the team, especially the relational conflict will affect the relationship between team members. But the happening of the conflict will make the perception of relational risk more obvious. The conflict has its positive side if handled properly. It can help to fully expose the problem within the project team and to get attention in time. What's more it can also provoke discussion within the team, clarify the different concerns among team members. Finally, the relational risk within the team will reduce.

Excepted from the conflict, in the cooperative innovation project team, trust also makes a difference. When the project team is full of confidence, cooperation relationship the probability of relational risk will be very low; on the contrary, the probability will be high.

It is undeniable, whether individuals, or the team, or large organizations, various kinds of problems mostly boil down to the lack of communication. In a team, apart from the exchange of work content, the existence of the problem will be clear by internal communication. It will be helpful to solve the problem.

H1: the relationship between the attitude, behavior of risk perception and relational risk is negatively related.

\subsubsection{The Relationship Hypothesis between the Level, Ability of Risk Perception and the Relational Risk}

In this study, the level, ability of risk perception is measured by the risk awareness, the level of risk control and the degree of risk exposure. The risk awareness level refers to the level of understanding for the relational risk within the project team. Good risk awareness can make team members perceive potential threats easily. Therefore, risk perception level is conducive to the perception of relational risk.

What's more, the relational risk control level refers to the processing capacity of relational risk factors within the team. For a variety of opportunism and moral behavior, the control level stands for the handing ability for these behaviors. One can imagine, for the control of these induction factors can effectively prevent the relational risk.

As we know, if a significant casualty occurred in a system which is familiar to the public, it may only cause a small social unrest. However, if in a strange system, it would bring great social influence. The emergence of these huge differences is mainly due to the different degree of exposure to risk factors. The more exposure to these factors, the awareness will be more clearly.

H2: the relationship between the level, ability of risk perception and relational risk is positively related.

\subsubsection{The Relationship Hypothesis between the Attitude, Behavior of Risk Perception and the Team Performance}

When conflict within the team occurs, if both sides have a good attitude or there is a good way to resolve the conflict, the happening of the conflict will let the internal problems expose clearly so that the organization's manager can deal with the problem properly, which is beneficial to the realization of performance.

Learning from the transaction cost theory, when the team is full of trust, the whole team will not use a lot of resources engaging in supervision and management so that the team could focus on cooperative innovation[11]; on the contrary, the team will spend more energy, material resources on the management, thus reducing the whole team performance.

From a certain extent, communication is productivity. Efficient internal communication not only can effectively prevent the occurrence of various risks from the source, may also be beneficial to propose and solve problems. In a team, the internal communication can communicate problems in cooperation, accurate understand management decisions of the project team, improve the work efficiency, resolve contradictions. All of these can guarantee or improve the performance level of the project team. 
According to the conclusions above, we put forward another hypothesis:

H3: the relationship between the attitude, behavior of risk perception and team performance is positively related.

\subsubsection{The Relationship Hypothesis between the Level, Ability of Risk Perception and the Team Performance}

If team members get high awareness of relational risk, they will continuously pay attention to the prevention of relational risk from their own, which makes the relational risk occurrence probability greatly reduced, so as to ensure the realization of project team performance[12].

The level of risk control is the ability to deal with the opportunistic or morally corrupt behavior. When the inducing factors of relational risk can be controlled effectively, it can greatly reduce the probability of risk occurrence of the relationship and promote the performances of the team.

When the risk factors are exposed to a great extent, the understanding of the risk factors will be profound and the perception will be clear[13]. In addition, the risk factors which are exposed frequently will make the management team to raise vigilance, and try to manage and control, so as to guarantee the performance of the project team

According to the three conclusions above, we put forward another hypothesis below.

$\mathrm{H} 4$ : the relationship between the level, ability of risk perception and team performance is positively related.

\section{The Process and Results of the Empirical Analysis}

\subsection{The Process of Investigation and Analysis of Samples}

The number of valid questionnaire is not very ideal. A total of 90 questionnaires issued, of which 48 valid questionnaires and the effective recovery rate is 53.3\%. According to the simple rules proposed by Bobby (2000): "In order to get a scientific analysis, the rate of the effective questionnaires should be at least 50\%”. According to Bobby's research, the collected data can be used to do a scientific analysis and research.

We measure the questionnaire survey by Cronbach's Alpha coefficient. For the following three variables: attitude and behavior of risk perception, the level and ability of risk perception, relational risk, we take the reliability analysis of 48 enterprises. The results are as follows Table 1.

From the table, the reliability values were more than 0.7 . It meets the reliability requirements.

\subsection{The Result of Structural Equation Model}

From the analysis above, we know the reliability and validity of the sample data are good. The main variables of the model fit well. So in this section, each variable's secondary index is classified as observation variables in structural equation model. Thus we establish the following Figure 2.

Table 1. The results of the reliability analysis.

\begin{tabular}{cccc}
\hline & \multicolumn{2}{c}{ Reliability statistics } & \\
& Cronbach's Alpha & Standard Cronbach's Alpha & Number of terms \\
$\begin{array}{c}\text { Variables of attitude and } \\
\text { behavior of risk perception }\end{array}$ & .843 & .846 & 13 \\
$\begin{array}{c}\text { Variables of level and ability of } \\
\text { risk perception } \\
\text { Variables of } \\
\text { relational risk }\end{array}$ & .767 & .767 & 8 \\
\hline
\end{tabular}

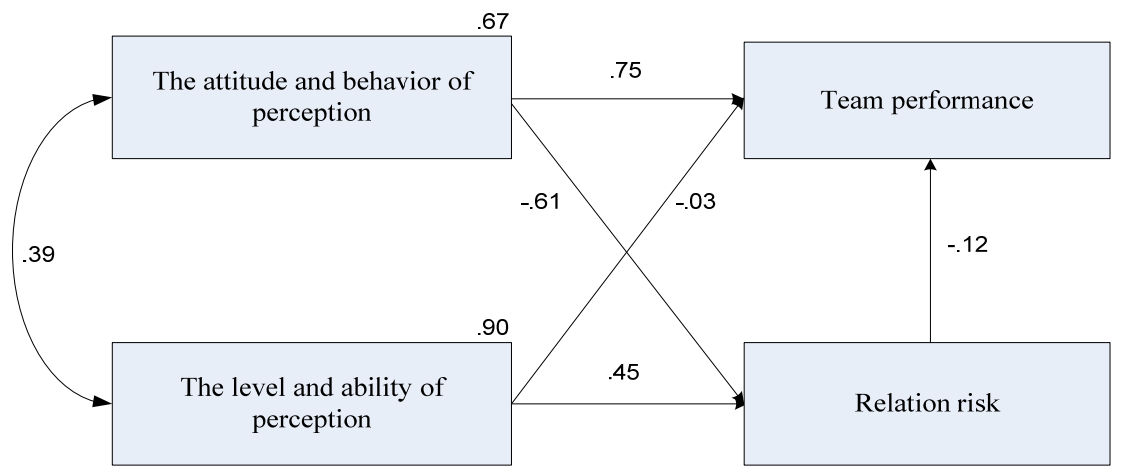

Figure 2. Relationship between the main variables of the model. 
The double-headed arrow in the model stands for the covariance of the two variables. The figures at the top right of the variable are the variance of each variable. As can be seen in the figure, no variance is negative value. It shows that there is no unreasonable parameter in the model estimation. In addition, taking the fit test for the model, the results are as follows Table 2 .

As the results can be seen, although the IFI, TLI $<0.9$, but they are in the vicinity of 0.9. The other indexes are in line with the requirements.

So the fitness of the model is good overall. Specific output data in Amos statements are as follows Table 3.

In the Table 4, the first column shows the regression coefficients which are not standardized; the second column shows the standard errors of the estimated parameters; the third column shows the test statistic. If this value is greater than 1.96, then it gets the significant level of 0.05; the fourth column shows the significance of the $\mathrm{P}$ value. If the $\mathrm{P}<.001$, it will be indicated by a symbol "****; if the $\mathrm{P}<.01$, it will be shown as “**”; if the $\mathrm{P}<.05$, it will be shown as “*”; if $\mathrm{P}>.05$, the $\mathrm{P}$ value will be shown directly.

The table above is for the covariance and covariance exogenous variables of the significance test. As $\mathrm{P}$ for the “***” indicates, covariance exogenous variables were significant at 0.05 level.

After the data testing, the assumptions mentioned above will be checked below. Here, we mainly verify the path relationship between the variables and the results are shown in Table 5.

\section{Conclusions and Implications}

According to the empirical analysis above, we get 4 conclusions:

1) The attitudes and behaviors of risk perception can effectively perceive relational risk may occur. It contains three observation variables: conflict, trust, internal communication. As data obtained from our analysis can be seen, attitude and behavior of risk perception has an important effect on relational risk $(\mathrm{P}<0.05)$. It indicates that the attitude and behavior of risk perception is a vital factor in the process of risk perception.

2) The level and ability of risk perception can effectively perceive relational risk may occur. It includes three observed variables: the understanding level, control level, degree of risk exposure. As the data shows, the level and ability of risk perception also has a remarkable effect on relational risk $(\mathrm{P}<0.05)$. It indicates that the level and ability of risk perception is also an important factor in the process of risk perception.

Table 2. The goodness-of-fit of the main variables.

\begin{tabular}{ccccccc}
\hline The index & 2/df & GFI & AGFI & IFI & TLI & RMSEA \\
\hline Result of fitting & 1.553 & .901 & .917 & .899 & .875 & .0408 \\
\hline
\end{tabular}

Table 3. Regression Weights: (Group number 1 - Default model).

\begin{tabular}{|c|c|c|c|c|c|c|c|}
\hline & & & Estimate & S.E. & C.R. & $\mathrm{P}$ & Label \\
\hline Relational risk & $<---$ & The attitude and ability of perception & -.611 & .251 & 2.434 & $*$ & par_2 \\
\hline Relational risk & $<---$ & The level and ability of perception & .454 & .216 & 2.101 & $* * *$ & par_4 \\
\hline Team performance & $<---$ & The attitude and ability of perception & .755 & .143 & 5.281 & $* *$ & par_1 \\
\hline Team performance & $<---$ & The level and ability of perception & -.032 & .121 & 4.267 & $* * *$ & par_3 \\
\hline
\end{tabular}

Table 4. Covariance: (Group number 1 - Default model).

\begin{tabular}{llllllll}
\hline & & Estimate & S.E. & C.R. & P & Label \\
\hline The attitude and ability of perception & $<->>$ & The level and ability of perception & .388 & .126 & 3.073 & $* * *$ & par_6 \\
\hline
\end{tabular}

Table 5. Hypothesis verification results.

\begin{tabular}{crrrcr}
\hline Hypothesis & Path relationship & Estimate & Correlation & Valid or not \\
\hline 1 & Relational risk<--- The attitude and behavior of perception & $-0.611^{*}$ & negative correlational & Valid & positive correlation \\
2 & Relational risk<--- The level and ability of perception & $0.454^{* * *}$ & Valid \\
3 & Team performance<--- The attitude and behavior of perception & $0.755^{* *}$ & positive correlation \\
4 & Team performance<--- The level and ability of perception & $-0.032^{* * *}$ & nalid & negative correlation \\
\hline
\end{tabular}


(3) Both the attitude, behavior of risk perception and the level, ability of risk perception have effects on relational risk. Moreover, these two variables interact with each other. In other words, if a team gets a positive attitude towards relational risk, it is likely to enhance their ability of risk identification. However, if a team only gets a positive attitude but in lack of relevant abilities, it may also fails in the relational risk identification.

\section{REFERENCES}

[1] J. Hagdoorn, "Research partnerships," Research Policy, 2000, Vol. 29, No. 4-5, pp. 567-586.

[2] Fritsch, Micheal, Lukas and W. Rolf, "Cooperates on R\&D,” Research Policy, Vol. 30, 2001, pp. 297-312.

[3] T. K. Das, Teng and B. Risk, "Types and Inter-firm Alliance Structures," Journal of Management Studies, Vol. 33, 1996, pp. 827-843.

[4] Nooteboom, B. Berger, N. G. H and Noorderhaven, "Effects of Trust and Governance on Relational Risk," Academy Management Journal, Vol. 40, No. 2, 1997, pp. 308-338.

[5] Helene delerue, "Relational Risks Perception in European Biotechnology Alliances: The Effect of Contextual Factors,” European Management Journal, Vol. 22, No. 5,
2004, pp. 546-556.

[6] Inkpen, "Learning and Knowledge Acquisition through International Strategic Alliance," Academy of Management Executive, 1998, pp. 69-80.

[7] Williamson, The Economic Institutions of Capitalism, NewYork Free Press, 1985, pp. 203-213.

[8] T. K. Das and B. S. Teng, “A Risk Perception Model of Alliance Structuring,” Journal of International Management, 2001, Vol. 7, pp. 1-29.

[9] T. K. Das and B. Teng, "Governance Structure Choice in Strategic Alliances Objectives: Alliance Management Experience and International Partners," Management Decision, 2008, pp. 1-33.

[10] S. White, "Cooperation Costs and Governance Choice and Alliance Evolution,” Journal of Management Studies, Vol. 42, 2005, pp. 1383-1412.

[11] A. Parkhe, "Strategic Alliances Structuring: a Game Theoretic and Transaction Cost Examination of Interfirm Cooperation,” Academy Management Journal, Vol. 36, No. 4, 1993, pp. 794-829.

[12] M. Granovetter, "Economic Action and Social Structure Embedness,” American Journal of Sociology, Vol. 91, No. 3, 1985, pp. 481-510.

[13] Homin Chena and Tain-Jychen, “Asymmetric Strategic Alliances: A Network View," Journal of Business Research, Vol. 55, 2002, pp. 1007-1013. 